\title{
REGISTRASI KEBUN DI DESA JELIJIH PUNGGANG KECAMATAN PUPUAN DALAM UPAYA MENUNJANG EKSPOR BUAH MANGGIS
}

\author{
I.M. Mega ${ }^{1}$, N.N. Soniari ${ }^{2}$, N.K. Seminari ${ }^{3}$ dan L.P. Wrasiati ${ }^{4}$
}

\begin{abstract}
ABSTRAK
Registrasi kebun manggis di desa Jelijih Punggang Kecamatan Pupuan dilakukan untuk memenuhi persyaratan ekspor buah manggis ke berbagai negara tujuan. Praktek pertanian yang baik dalam teknik budidaya tanaman meliputi seleksi bibit berkualitas, pembuatan lubang tanam, pengendalian hama dan penyakit, pemupukan yang tepat, serta pemeliharaan kebun berbasis organik sehingga menghasilkan buah berkualitas. Usaha peningkatan kualitas buah tidak hanya dilakukan saat budidaya namun pada waktu pemetikan/panen buah memerlukan alat panen yang tidak melukai kulit buah sehingga tampilan buah menjadi mulus dan cantik. Registrasi kebun merupakan salah satu cara untuk meningkatkan kualitas dan kuantitas produk agar berdaya saing tinggi dan hal ini sejalan dengan salah satu tujuan dari Program Pengembangan Produk Unggulan Daerah (PPPUD). Metode pelaksanaan dalam pencapaian hal tersebut di atas adalah dengan sosialisasi, komunikasi, pendampingan teknologi pada kelompok sasaran. Pendampingan kelompok tani diperlukan untuk meningkatkan produktivitas buah manggis yang berkelanjutan, dengan pelatihan manajemen usaha tani, dan penangannan pascapanen pada saat panen raya dengan pengolahan produk sisa ekspor menjadi produk baru yang bernilai jual lebih tinggi. Respon kelompok tani dan mitra UMKM sangat antusias dalam menerima inovasi dan melakukan Good Agricultural Practices, serta meningkatkan pengetahuan dan keterampilan melalui pelatihan.
\end{abstract}

Kata kunci : registrasi kebun, manggis, PPPUD, UMKM, ekspor

\begin{abstract}
Mangosteen garden registration in the village of Jelijih Punggang Pupuan District is carried out to fulfill the export requirements of mangosteen fruit to various destination countries. Good agricultural practices in crop cultivation techniques include selection of quality seeds, making a planting hole, pest and disease control, proper fertilization, and maintenance of organic-based gardens so as to produce quality fruit. Efforts to improve the quality of fruit are not only done during cultivation but at the time of picking / harvesting the fruit requires a harvesting tool that does not hurt the skin of the fruit so that the appearance of the fruit becomes smooth and beautiful. Plantation registration is one way to improve the quality and quantity of products to be highly competitive and this is in line with one of the objectives of the Regional Superior Product Development Program (PPPUD). The method of implementation in achieving the above is through socialization, communication, technological assistance to the target group. Assistance to farmer groups is needed to increase sustainable mangosteen productivity, with training in farm management, and postharvest handling at harvest time by processing leftover export products into new products of higher selling value.
\end{abstract}

${ }^{1}$ Program Studi Agroekoteknologi Fakultas Pertanian Universitas Udayana, mademega@unud.ac.id

2 Program Studi Agroekoteknologi Fakultas Pertanian Universitas Udayana, nengahsoniari@ unud.ac.id

${ }^{3}$ Program Studi Manajemen Fakultas Ekonomi dan Bisnis Universitas Udayana, ketutseminari@yahoo.com

${ }^{4}$ Fakultas Teknologi Pertanian Universitas Udayana,wrasiati@unud.ac.id 
The response of farmer groups and UMKM partners was very enthusiastic in accepting innovations and conducting Good Agricultural Practices, as well as increasing knowledge and skills through training.

Keyword : garden registration, mangosteen, PPPUD, UMKM, export

\section{PENDAHULUAN}

Budidaya tanaman manggis di wilayah Desa Jelijih Punggang Kecamatan Pupuan umumnya kurang intensif atau belum menerapkan Good Agriculture Paractice (GAP). Penerapan teknologi budidaya relative sangat minim, petani sangat jarang memupuk tanaman begitu pula dakam perawatan tanaman sangat jarang dilakukan. Kondisi tersebut menjadikan produktifitas tanaman menjadi sangat rendah hanya $20-30 \mathrm{~kg} /$ pohon. Tindakan budidaya yang belum memenuhi GAP tersebut menyebabkan lahan kebun manggis ini belum tersertifikasi.

Nyoman Genep mengatakan bahwa Sertifikasi atau registrasi kebun merupakan upaya penyusunan "data base" kebun yang telah menerapkan Good agricultural practices (GAP) dalam teknik budidaya melalui pemilihan bibit berkualitas, pembuatan lubang tanam,pemupukan, pengendalian hama dan pmeliharaan tanaman dengan baik serta berbasis organik sehingga buahnya bagus (Adnyana, 2018) . Menurut Badan Karantina Pertanian, Kementan RI (2014), bahwa kebun terregistrasi adalah kebun yang telah diidentifikasi, diaudit secara internal, dinilai, serta telah memenuhi semua dokumen persyaratan dan telah mendapatkan nomor penghargaan dari otoritas kompeten.

Data sertifikasi kebun manggis merupakan persyaratan dalam menembus pasar ekspor buah manggis. Oleh karena itu kegiatan PPPUD manggis untuk ekspor melakukan sertifkasi kebun agar buah manggis di wilayah Desa Jelijih Punggang dapat ditingkatkan kualitas dan nilai ekspornya.

\section{METODE PELAKSANAAN}

Metode yang diterapkan dalam pemberdayaan masyarakat ini adalah sebagai berikut: (1) Sosialisasi , koordinasi dan komunikasi secara partisipasif dengan pengola UKM Mitra untuk merumuskan program mulai dari perencanaan, operasional dan evaluasi; (2) mengumpulkan informasi tentang kebun yang meliputi : nama pemilik lahan, luas lahan, jumlah tanaman manggis baik yang berproduksi maupun yang belum berproduksi, jumlah produksinya per pohon, dan lainlain melalui survai ke lahan kebun manggis dan anggota kelompok tani. 3) Mentabulasi data hasil survai dan selanjutnya diajukan ke Dinas Pertanian Tanaman Pangan, Hortikultura dan Perkebunan Propinsi Bali.

\section{HASIL DAN PEMBAHASAN}

Mengawali kegiatan ini tim PPPUD melakukan sosialisasi program ke Pemkab Tabanan, untuk dapat berkoordinasi serta dukungan legitimasi (Gambar 3.1.). Sertifikasi kebun yaitu mendata atau meregistrasi kebun manggis yang ada di wilayah Desa Jelijih Punggang. Registrasi ini meliputi : nama pemilik, luas areal (ha), jumlah tanaman (pohon), jumlah tanaman yang belum berbuah/menghasilkan (TBB/pohon), jumlah tanaman yang sudah berbuah (TB/pohon), rata-rata produksi $(\mathrm{kg})$, jumlah produksi $(\mathrm{kg})$.

Hasil kegiatan berupa data registrasi/sertifikasi sebagian kebun manggis di wilayah Desa Jelijih Punggang, yaitu : luas kebun 30,99 ha, jumlah tanaman 1.854 pohon (tanaman belum berproduksi 
466 pohon dan 1.388 pohon sudah berproduksi) dengan total produksi $69.400 \mathrm{~kg}$. Adapun data selengkapnya disajikan pada Tabel berikut:

Tabel 1. Data Registrasi Kebun

\begin{tabular}{|l|l|c|c|c|c|c|c|}
\hline No. & Nama Anggota & $\begin{array}{l}\text { Luas } \\
\text { lahan } \\
(\mathrm{ha})\end{array}$ & $\begin{array}{l}\text { Jumlah } \\
\text { tanaman } \\
(\mathrm{ph})\end{array}$ & $\begin{array}{l}\text { Jumlah } \\
\text { TBB } \\
(\mathrm{ph})\end{array}$ & $\begin{array}{l}\text { Jumlah } \\
\text { TB }(\mathrm{ph})\end{array}$ & $\begin{array}{l}\text { Rata-rata } \\
\text { produksi/ } \\
\text { ph (kg) }\end{array}$ & $\begin{array}{l}\text { Jumlah } \\
\text { produksi } \\
(\mathrm{kg})\end{array}$ \\
\hline 1 & I Wayan Artawijaya & 0,50 & 65 & 15 & 50 & 50 & 2500 \\
\hline 2 & I Nyoman Santiasa & 0,60 & 40 & 10 & 30 & 50 & 1500 \\
\hline 3 & I Nyoman Winartajaya & 0,86 & 55 & 10 & 45 & 50 & 2250 \\
\hline 4 & I Ketut Suantra & 0,49 & 60 & 15 & 45 & 50 & 2250 \\
\hline 5 & I Ketut Sukaja & 1,60 & 95 & 25 & 70 & 50 & 3500 \\
\hline 6 & I Wayan Sutanaya & 1,42 & 60 & 10 & 50 & 50 & 2500 \\
\hline 7 & I Nyoman Suara & 1,00 & 45 & 0 & 45 & 50 & 2250 \\
\hline 8 & I Made Arsana & 1,24 & 45 & 15 & 30 & 50 & 1500 \\
\hline 9 & I Made Bagiantara & 1,44 & 80 & 10 & 70 & 50 & 3500 \\
\hline 10 & I Ketut Suatra & 0,63 & 45 & 15 & 30 & 50 & 1500 \\
\hline 11 & I Wayan Pastika & 0,50 & 30 & 6 & 24 & 50 & 1200 \\
\hline 12 & I Ketut Nona & 0,37 & 61 & 16 & 45 & 50 & 2250 \\
\hline 13 & I Ketut Regog & 0,75 & 40 & 20 & 20 & 50 & 1000 \\
\hline 14 & I Nyoman Sudana & 0,92 & 50 & 10 & 40 & 50 & 2000 \\
\hline 15 & I Nengah Antarayasa & 0,82 & 57 & 22 & 35 & 50 & 1750 \\
\hline 16 & I Made Sumia & 1,73 & 50 & 10 & 40 & 50 & 2000 \\
\hline 17 & I Nyoman Suartana & 0,50 & 20 & 6 & 14 & 50 & 700 \\
\hline 18 & I Made Suarta & 0,63 & 45 & 15 & 30 & 50 & 1500 \\
\hline 19 & I Ketut Sumirta & 1,58 & 100 & 25 & 75 & 50 & 3750 \\
\hline 20 & I Made Suama & 1,76 & 60 & 20 & 40 & 50 & 2000 \\
\hline 21 & I Wayan Suardana & 0,95 & 165 & 20 & 145 & 50 & 7250 \\
\hline 22 & I Made Warmada & 2,47 & 50 & 20 & 30 & 50 & 1500 \\
\hline 23 & I Ketut Gelis & 0,50 & 40 & 10 & 30 & 50 & 1500 \\
\hline 24 & I Nengah Warsa & 1,08 & 65 & 15 & 50 & 50 & 2500 \\
\hline 25 & I Gede Oka Adnyana & 0,80 & 55 & 10 & 45 & 50 & 2250 \\
\hline 26 & I Wayan Rudiana & 1,21 & 70 & 30 & 40 & 50 & 2000 \\
\hline 27 & I Nyoman Sri Adnyana SS & 0,50 & 30 & 15 & 15 & 50 & 750 \\
\hline 28 & I Ketut Suama & 1,00 & 48 & 8 & 40 & 50 & 2000 \\
\hline 29 & I Nyoman Sukanada & 0,60 & 30 & 10 & 20 & 50 & 1000 \\
\hline 30 & I Wayan Darmawan & 0,65 & 80 & 15 & 65 & 50 & 3250 \\
\hline 31 & I Made Sujaya & 1,37 & 68 & 18 & 50 & 50 & 2500 \\
\hline 32 & I Wayan Suaja & 0,52 & 50 & 20 & 30 & 50 & 1500 \\
\hline & Total & 30,99 & 1854 & 466 & 1388 & 1600 & 69400 \\
\hline & & & & & & & \\
\hline
\end{tabular}

Registrasi kebun ini memberi manfaat kepada petani dalam peningkatan pengetahuan pengelolaan kebun, penyaluran /pemasaran, keabsahan , serta kelayakan produknya baik dari segi kualitas, kuantitas dan kontinyuitas sebagai komoditi ekspor maupun pemasaran di dalam negeri (Gambar 3.2.) 


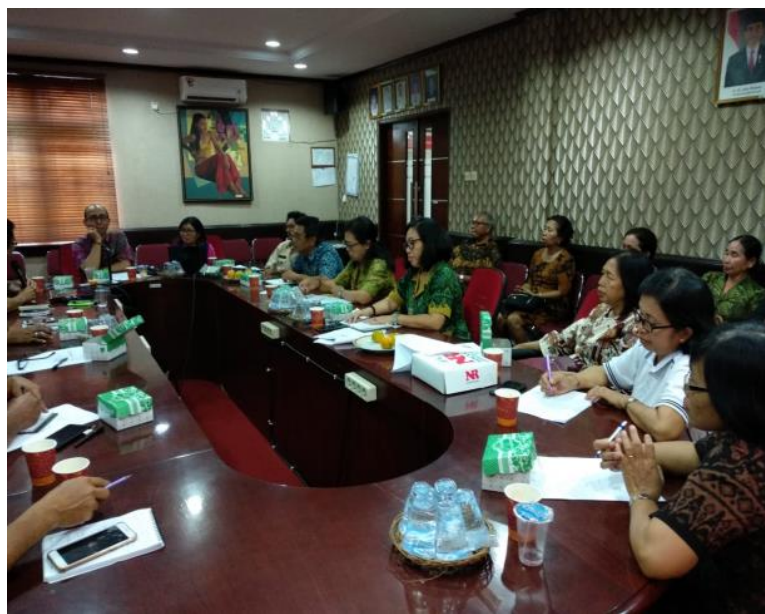

Gambar 3.1.Sosialisasi Program di Pemkab Tabanan

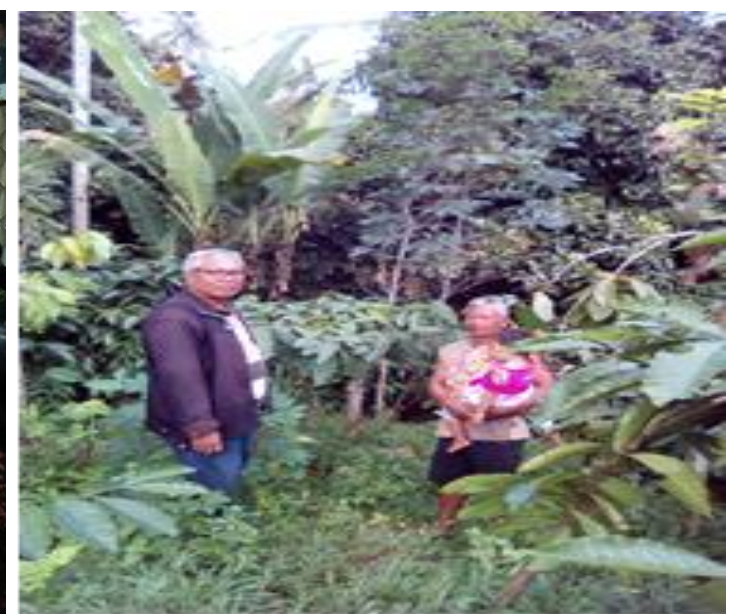

Gambar 3.2. Pendataan Kebun

Selanjutnya pendampingan ditujukan untuk penanganan panen dengan memberikan alat bantu panen buah ( fruit picker ) supaya buah yang dipanen tidak terluka (Gambar 3. 2.), sedangkan untuk pasca panen, tim menyumbangkan kompresor air mini untuk pencucian buah sehingga bersih dari hama dan pencemar lainnya sehingga layak konsumsi.(Gambar 3.3.)

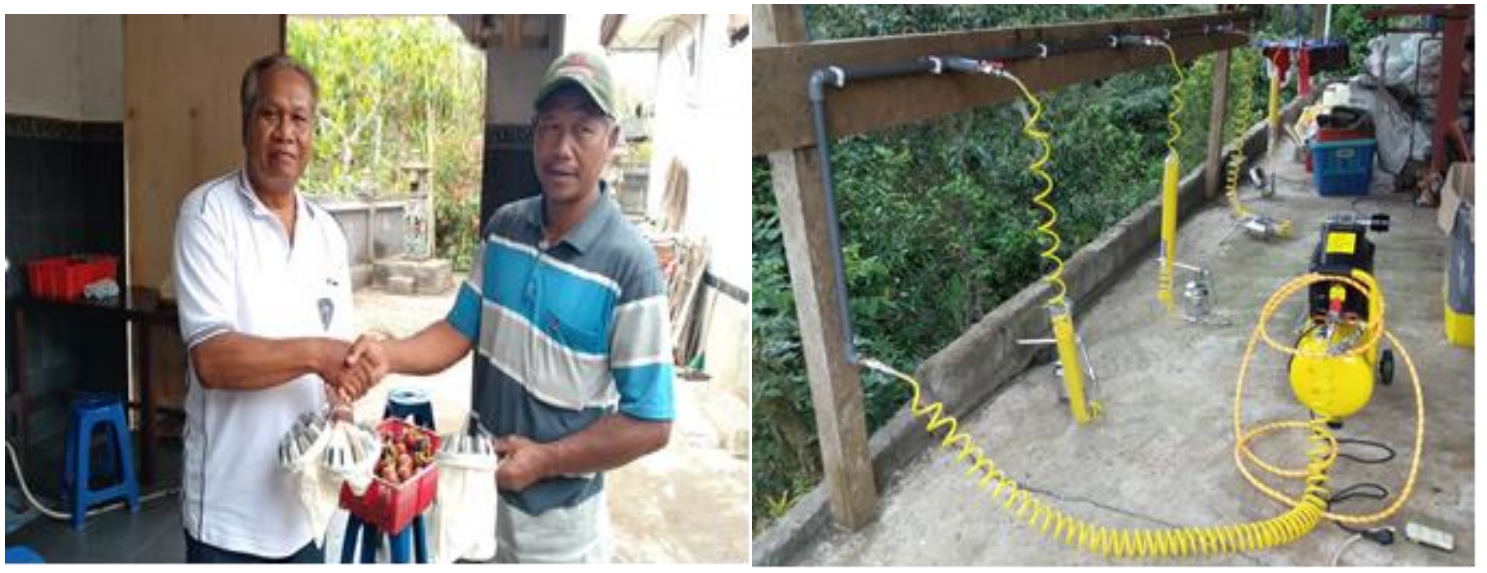

Gambar 3.3 Penyerahan Fruit Picker
Gambar 3.4. Kompresor air mini

Tim PPPUD juga melakukan pendampingan terhadap mitra (UD.Gunung Sari), yang mengolah manggis sisa ekspor (grade 2 dan 3), seperti daging kulit buah manggis diolah menjadi juice dan daging buah dijadikan minuman sari buah segar. Pendampingan ini menyertakan anggota tim dari Fakultas Teknologi Pertanian. UMKM ini menampung hasil panen buah manggis sisa ekspor di saat panen raya. Berkaitan dengan hal itu, tim menyumbangkan tangki fermentasi double jacket untuk kestabilan suhu saat fermentasi.( Gambar 3. 5.). Pelatihan manajemen usaha juga dilakukan oleh anggota tim PPPUD dari Fakultas Ekonomi dan Bisnis yang bertujuan untuk mempersiapkan administrasi (pembukuan) yang teratur dan rapi, tips mengelola suatu usaha dari perencanaan hingga pemasaran.(Gambar 3. 6.). Pendampingan terus dilakukan oleh tim sehingga tujuan program pemberdayaan masyarakat melalui peningkatan eksistensi produk unggulan daerah oleh kelompok petani manggis dan mitra UMKM tercapai. 


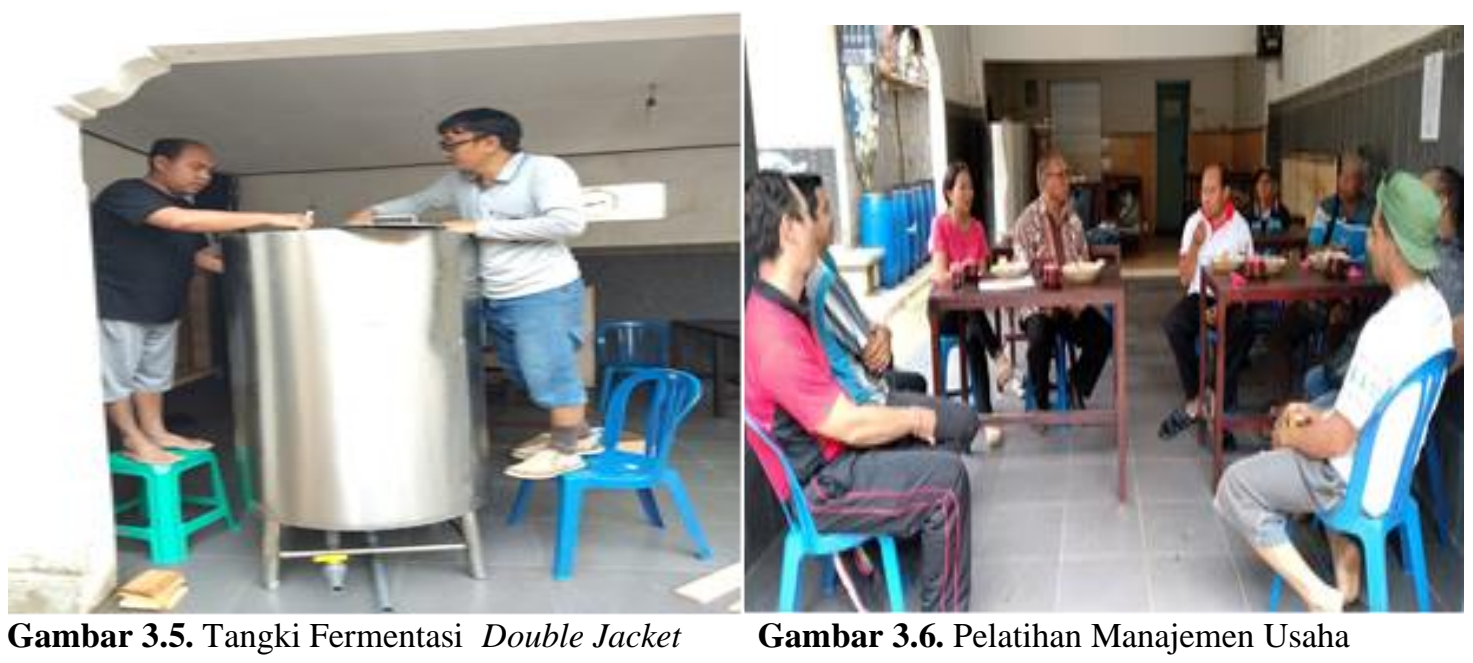

\section{KESIMPULAN DAN SARAN}

\section{Kesimpulan}

Berdasarkan kegiatan pada Program Pengembangan Produk Unggulan daerah yang telah dilaksanakan di Desa Jelijih Punggang, dapat disimpulkan beberapa hal sebagai berikut :

1. Kelompok tani di desa Jelijih Punggang Kecamatan Pupuan Tabanan sangat responsive terhadap program registrasi kebun untuk menunjang kelancaran ekspor manggis ke manca Negara.

2. Tim bekerjasama dengan Pemerintah Kabupaten Tabanan mengawal dan memfasilitasi registrasi kebun dengan pendampingan good agricultural practices.

3. Pendampingan mitra "UD Gunung Sari" dalam pembuatan juice manggis yang memenuhi standar PIRT, penyempurnaan proses fermentasi, pengemasan, serta perbaikan manajemen usaha telah dilakukan tim.

\section{Saran}

Peluang pengembangan produk olahan manggis menjadi berbagai produk baru masih mungkin dilakukan, dengan demikian kerjasama perguruan tinggi dalam melakukan pendampingan teknologi sangat diperlukan

\section{UCAPAN TERIMA KASIH}

Tim mengucapkan terimakasih kepada Direktorat Riset dan Pengabdian Masyarakat Kemenristek Dikti atas dana yang telah diberikan, Ketua Lembaga Pengabdian Masyarakat Universitas Udayana, Pemda Tabanan serta Masyarakat Desa Jelijih Punggang atas kerjasamanya sehingga program ini berjalan dengan baik

\section{DAFTAR PUSTAKA}

Adnyana, M.2018. Tiga Kelompok Tani Manggis di Buleleng Terima Sertifikat Registrasi. https://bali, antaranews.com/berita/133844/tiga-kelompok-tani-manggis-di-buleleng-terima-sertifikat-registrasi

Badan Karantina Pertanian Kementan RI(2014) Pedoman Sertifikasi Fitosanitari Buah Manggis Tujuan Australia (Pedoman Sertifikasi Fitosanitari Buah Manggis Tujuan Australia) Jakarta.

Sardiana, IK., BRT Putri, IG Suranjaya, NLR Purnawan. 2015. Pengembangan Kewirausahaan di Universitas Udayana. Ngayah: Majalah Aplikasi IPTEKS 6 (1) 
Registrasi Kebun di Desa Jelijih Punggang Kecamatan Pupuan Dalam Upaya Menunjang Ekspor

Buah Manggis

http://www.usahid.ac.id/wp-content/uploads/2017/03/BAB-20.Pedoman Penelitian dan Pengabdian Kepada Masyarakat Edisi X. RISTEKDIKTI.

http://www.balipost.com/news/2018/02/06/36736/Registrasi-Kebun-Manggis-Terhalang-Pemenuhan...html.

Diakses tanggal 5 Oktober 2019 